\title{
Effect of Porous Thrust Surfaces on Detonation Transition and Detonation Tube Impulse
}

\author{
M. Cooper* and J. E. Shepherd ${ }^{\dagger}$ \\ California Institute of Technology, Pasadena, CA 91125
}

\begin{abstract}
As pulse detonation engine development matures, it becomes increasingly important to consider how practical details such as the implementation of valves and nozzles will affect performance. Inlet valve timing and valveless inlet designs may result in flow of products back upstream and, consequently, reduction in impulse over the ideal case. Although proper inlet design or operation under flowing conditions may minimize these losses, our study addresses the worst-case effect that a porous thrust surface may have on the measured impulse. A series of singlecycle tests have been carried out to measure the impulse in stoichiometric ethylene-oxygen mixtures, initially between 20 and $100 \mathrm{kPa}$, in a detonation tube with a porous thrust surface. The tested thrust surfaces had blockage ratios ranging from completely solid (100\% blockage ratio) to completely open (0\% blockage ratio). A $76 \%$ loss in impulse was observed with a thrust surface blockage ratio of $52 \%$ at an initial pressure of $100 \mathrm{kPa}$. The time to detonation transition was found to be more dependent on the mixture's initial pressure than on the thrust surface blockage ratio. A model of the impulse in detonation tubes with porous thrust surfaces was developed.
\end{abstract}

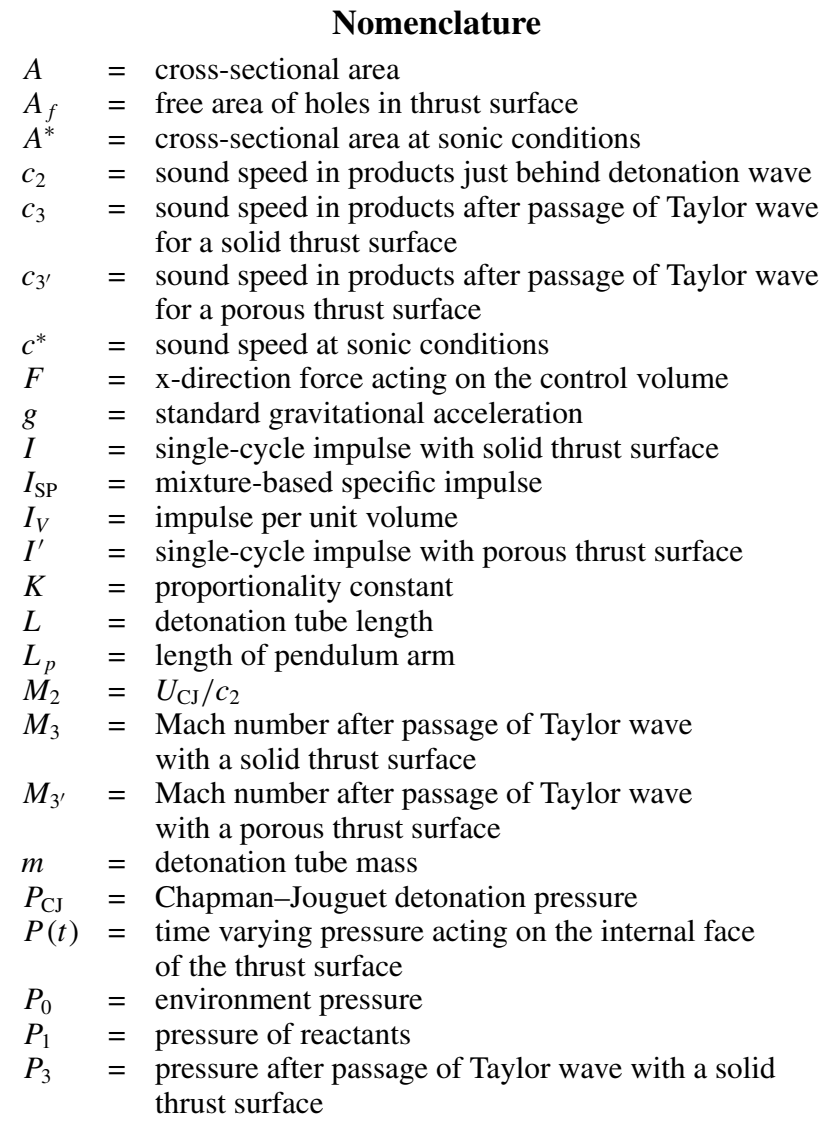

Presented as Paper 2003-4822 at the AIAA/ASME/SAE/ASEE 39th Joint Propulsion Conference and Exhibit, Huntsville, AL, 20-23 July 2003; received 8 September 2003; revision received 18 December 2003; accepted for publication 19 December 2003. Copyright (C) 2004 by California Institute of Technology. Published by the American Institute of Aeronautics and Astronautics, Inc., with permission. Copies of this paper may be made for personal or internal use, on condition that the copier pay the $\$ 10.00$ per-copy fee to the Copyright Clearance Center, Inc., 222 Rosewood Drive, Danvers, MA 01923; include the code $/ 04 \$ 10.00$ in correspondence with the CCC.

* Graduate Student, Mechanical Engineering, Graduate Aeronautical Laboratories. Member AIAA.

${ }^{\dagger}$ Professor, Aeronautics, Graduate Aeronautical Laboratories. Member AIAA.

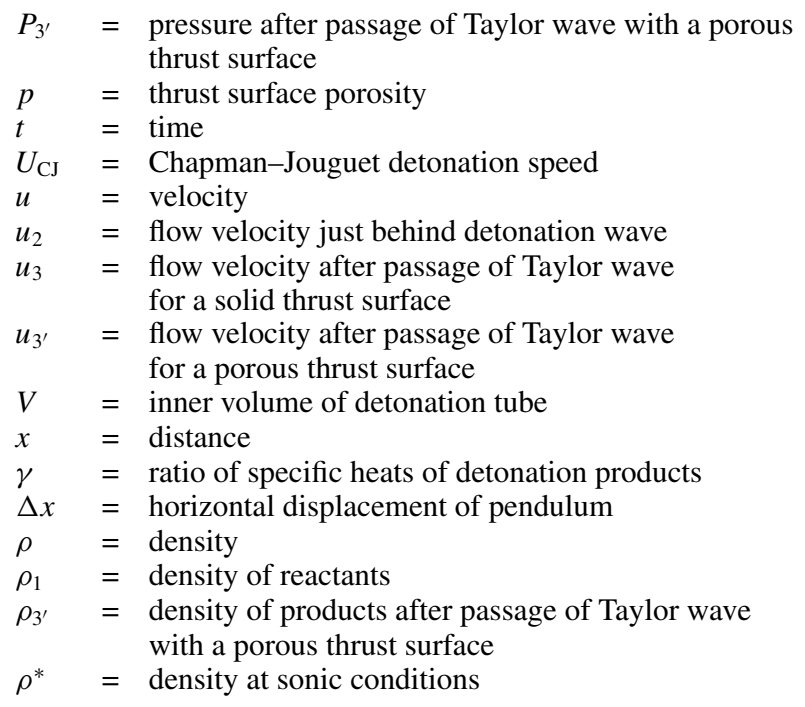

\section{Introduction}

S pulse detonation engine (PDE) development progresses, in$A$ creasing attention is being placed on inlet valves and other upstream flow features. Previous single-cycle experimental studies ${ }^{1-7}$ have been conducted with simplified detonation tube geometries and have quantified the impulse obtained from a variety of combustible mixtures at varying initial pressures and dilution amounts, in addition to investigating the effect of internal obstacles, ${ }^{1,2}$ deflagration to detonation transition (DDT) distance, ${ }^{1,3}$ and attached nozzles ${ }^{1,4-7}$ on impulse.

In these experiments, however, the detonation tube thrust surface was solid (100\% blockage ratio) and all exhaust flow was forced to exit through the open end of the tube. In a practical multicycle application, the thrust surface of the tube will not be solid because a fresh combustible mixture must be repeatedly injected. A variety of inlet designs ${ }^{4,8-11}$ and mechanical valves have already been implemented into multicycle test facilities.

Because of the many variations in inlet design, the actual loss in impulse must be determined on an individual basis. It is possible, with proper inlet design, that the impulse may not be transferred to a thrust surface in the typical sense, but to another part of the engine. Valveless PDEs that operate under flowing conditions in which the upstream flow is choked could be thought of as fluidic thrust surfaces, where losses in impulse are minimized. Nonoptimum inlet design may significantly affect the measured impulse 
even for relatively small values of thrust surface porosity. Improper valve timing could result in open valves while the detonation is propagating the length of the tube, resulting in product gas exhaust out through the inlet valves. To study this aspect of PDE performance, we have selected the simplest possible geometry that will show this effect. This study is conducted in a nonflowing, single-cycle detonation tube that is closed by a porous plate at the thrust end and open at the opposite end. We used the ballistic pendulum technique to determine experimentally the impulse and have developed a simple model to predict the impulse given the thrust surface blockage ratio. The impulse results obtained are considered to be the worst case and can be used to bound any losses in impulse that may occur due to the physical dimensions of a PDE inlet.

\section{Experimental Setup}

Tests were conducted in a detonation tube of constant circular cross section (Fig. 1). The tube had an inner diameter of $76.2 \mathrm{~mm}$, a length of $1.057 \mathrm{~m}$, and did not contain internal obstacles. A porous (or solid) thrust surface was installed at one end of the tube near the spark plug and sealed with a $25-\mu$ m-thick Mylar ${ }^{\circledR}$ diaphragm. A fixture was built that enabled different thrust surfaces to be exchanged easily. The exhaust end was open, but initially sealed with a second 25- $\mu \mathrm{m}$-thick Mylar diaphragm. Direct impulse measurements were made by hanging the tube from the ceiling in a ballistic pendulum arrangement with four steel wires. The tube's maximum horizontal deflection $\Delta x$ was recorded and used to calculate the impulse:

$$
I=m \sqrt{2 g L_{p}\left[1-\sqrt{1-\left(\Delta x / L_{p}\right)^{2}}\right]}
$$

The experimental uncertainty associated with the single-cycle impulse measured in this fashion was estimated to be $\pm 6.4 \%$ for cases of fast DDT. ${ }^{1}$

A spark plug and associated discharge system with $30 \mathrm{~mJ}$ of stored energy was used to ignite the combustible mixture at a distance of $43.4 \mathrm{~mm}$ from the internal edge of the thrust surface. Combustion products were free to exhaust from the tube's open end and through the porous thrust surface into a large $\left(\simeq 50-\mathrm{m}^{3}\right)$ blast-proof room. Diagnostics on the detonation tube included 4 pressure transducers and 10 ionization gauges.

Each test began with the installation of a diaphragm at both ends of the tube and its evacuation to a pressure less than $27 \mathrm{~Pa}$. A 14-liter vessel was filled with stoichiometric ethylene-oxygen by the method of partial pressures and mixed for at least 5 min to ensure homogeneity. The detonation tube was then filled with this premixed gas to an initial pressure between 20 and $100 \mathrm{kPa}$.

Each thrust surface consisted of a 19.1-mm-thick aluminum circular plate with an arrangement of through-holes drilled to yield the desired porosity. Three different hole arrangements (Fig. 2), were tested on a total of nine different thrust surfaces. The thrust surface porosity $p$ is defined as the area of the holes $A_{f}$ divided by the exposed area of the thrust surface $A$ (equal to the detonation tube cross-sectional area). Alternatively, the blockage ratio (BR) is defined as the blocked area divided by the maximum free area possible on the thrust surface, or,

$$
\mathrm{BR}=1-p=1-\left(A_{f} / A\right)
$$

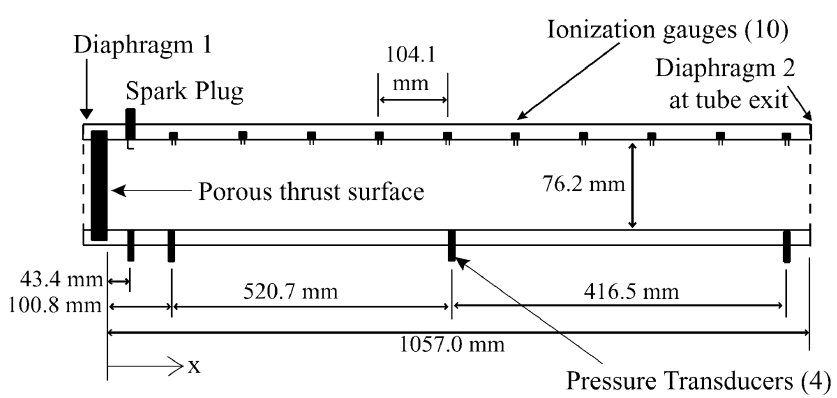

Fig. 1 Schematic of the experimental detonation tube with porous thrust surface.
Table 1 Blockage ratios and porosities of experimental thrust surfaces

\begin{tabular}{lcc}
\hline \hline Configuration & $\mathrm{BR}, \%$ & $p, \%$ \\
\hline Solid & 100 & 0 \\
4-Hole & 88.9 & 11.1 \\
7-Hole & 89.1 & 10.9 \\
7-Hole & 85.1 & 14.9 \\
7-Hole & 80.6 & 19.4 \\
7-Hole & 75.3 & 24.6 \\
7-Hole & 64.9 & 35.1 \\
7-Hole & 52.5 & 47.5 \\
Open & 0 & 100 \\
\hline \hline
\end{tabular}

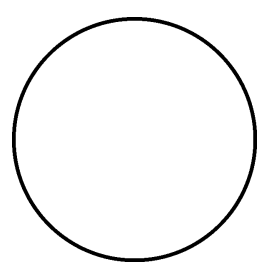

a)

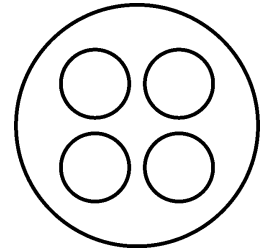

b)

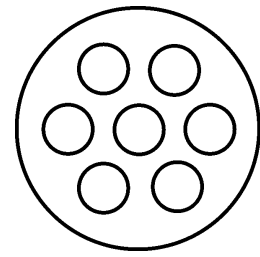

c)
Fig. 2 Porous thrust surfaces with a) solid configuration, b) 4-hole configuration, and c) 7-hole configuration.

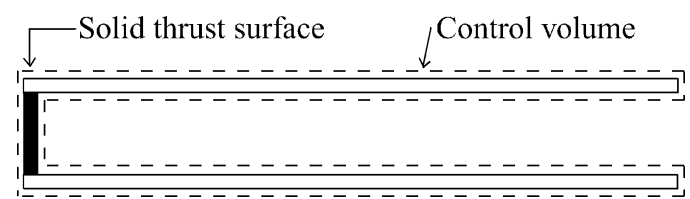

Fig. 3 Control volume for a detonation tube with a solid thrust surface.

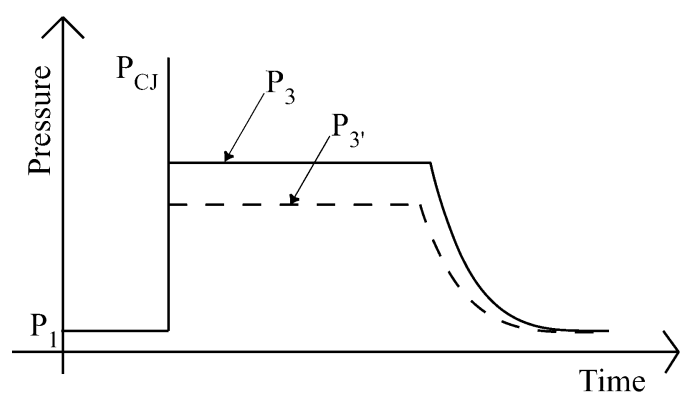

Fig. 4 Thrust surface pressure history for solid and porous thrust surfaces. Solid lines correspond to the case of a solid thrust surface and the dashed lines correspond to the case of a porous thrust surface.

Specifics of the experimental thrust surfaces appear in Table 1. The blockage ratios ranged from solid $(100 \% \mathrm{BR})$ to completely open (0\% BR).

\section{Impulse Modeling}

The impulse from a single-cycle detonation tube with a solid thrust surface has been modeled by Wintenberger et al. ${ }^{12}$ and is based on a control volume surrounding the detonation tube (Fig. 3). The impulse is obtained by integration of the forces acting on the control volume:

$$
I=\int F \mathrm{~d} t=\int\left[P(t)-P_{0}\right] A \mathrm{~d} t
$$

where $P(t)$ is the time-varying pressure acting on the internal face of the thrust surface. This pressure is evaluated by prediction ${ }^{12}$ of the internal flowfield of the detonation tube with one-dimensional gasdynamics, given instantaneous detonation initiation. A schematic of the idealized thrust surface pressure $P(t)$ appears as the solid line in Fig. 4. Detonation initiation is denoted by the pressure spike to $P_{\mathrm{CJ}}$ followed by a region of constant pressure denoted by $P_{3}$. 


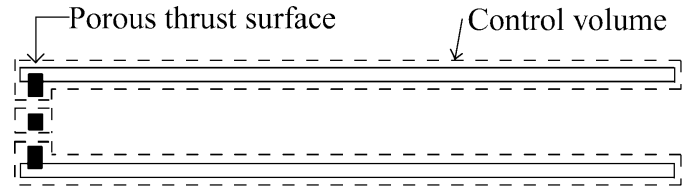

Fig. 5 Control volume for a detonation tube with a porous thrust surface.

This plateau pressure is followed by a region of decreasing pressure as the detonation products exhaust from the tube. The thrust surface pressure history can be integrated exactly to determine the maximum impulse, and the predictions are found to agree within $\pm 15 \%$ of experimental data. ${ }^{12}$ Alternatively, the results of the exact integration can be approximated by

$$
I=\left(K V / U_{\mathrm{CJ}}\right)\left(P_{3}-P_{0}\right)
$$

which depends on only a few detonation parameters specific to a given initial mixture and can reproduce the predictions of the detailed model to within $2.5 \%$ (Ref. 12). The volume $V$ represents the product of the tube cross-sectional area $A$ and the tube length $L$. The proportionality constant $K$ is 4.3 . Wintenberger et al. ${ }^{12}$ provide a detailed discussion of the model formulation and extensive validation.

Consider now the case of a detonation tube with a porous thrust surface. We modify the earlier control volume to account for the open area of the thrust surface (Fig. 5). The impulse is determined by integration of the forces on the control volume in the same manner as it was earlier:

$$
I^{\prime}=\int F^{\prime} \mathrm{d} t=\int\left[P^{\prime}(t)-P_{0}\right] A^{\prime} \mathrm{d} t
$$

We denote the terms specific to the case with a porous thrust surface with a prime. The instantaneous pressure $P^{\prime}(t)$ is shown schematically as the dashed line of Fig. 4. The thrust surface area $A^{\prime}$ represents the thrust surface area that is blocked.

$$
A^{\prime}=A-A_{f}=A\left(1-A_{f} / A\right)
$$

Thus, the impulse integral becomes

$$
I^{\prime}=\int\left[P^{\prime}(t)-P_{0}\right] A\left(1-\frac{A_{f}}{A}\right) \mathrm{d} t
$$

Because of the similarity between the impulse integrals for the cases with a solid and porous thrust surface, we propose a modification to the existing impulse model [Eq. (4)] to account for the effect of a porous thrust surface:

$$
I^{\prime}=\left(K V / U_{\mathrm{CJ}}\right)\left(P_{3^{\prime}}-P_{0}\right)\left[1-\left(A_{f} / A\right)\right]
$$

The volume $V$ still refers to the product of the cross-sectional tube area $A$ and the tube length $L$. To evaluate the plateau pressure $P_{3^{\prime}}$, we need to evaluate the internal flowfield for a tube with a porous thrust surface.

\section{Internal Flowfield}

When the detonation tube contains a solid thrust surface, the detonation (initiated at or near the thrust surface) propagates the length of the tube, followed by an expansion wave called the Taylor wave. This is illustrated by a distance-time diagram in Fig. 6 . The reactant state is labeled on Fig. 6 as state 1. State 2 is the Chapman-Jouguet state just behind the detonation wave, where the lab frame velocity is $u_{2}$. Because the flow velocity of a particle next to the solid thrust surface must be zero, the Taylor wave isentropically expands the flow from $u_{2}$ at the detonation front to zero at the thrust surface. This is denoted by state 3 , where $u_{3}$ is zero (Fig. 6). A corresponding pressure decrease occurs through the Taylor wave from the Chapman-Jouguet pressure $P_{\mathrm{CJ}}$ to the plateau pressure $P_{3}$ (Fig. 4). All detonation products begin to exhaust out the tube exit after the detonation wave transmits a nonreactive shock into the surroundings and a reflected wave back to the thrust surface (not shown in Fig. 6).

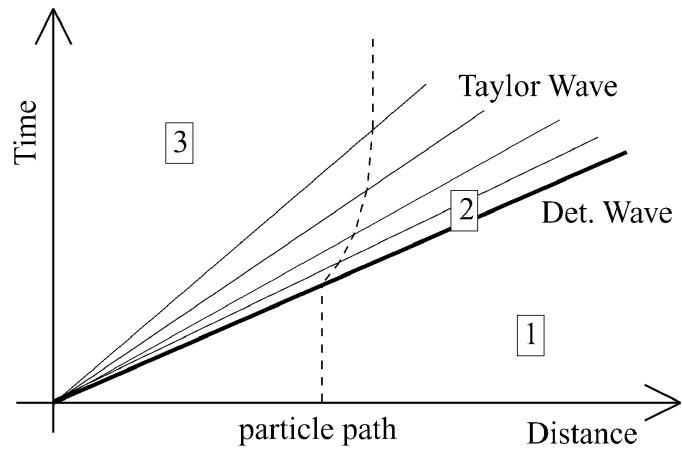

Fig. 6 Distance-time diagram for a detonation tube with a solid thrust surface.

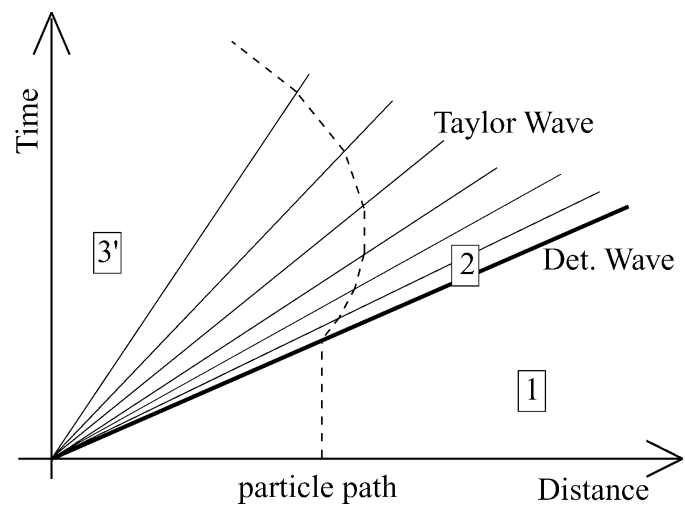

Fig. 7 Distance-time diagram for a detonation tube with a porous thrust surface.

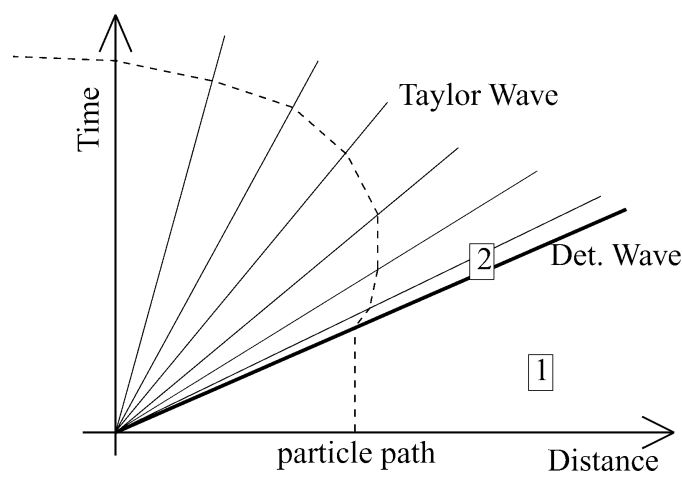

Fig. 8 Distance-time diagram for a detonation tube with a completely open thrust surface; leftmost $C^{+}$characteristic is sonic and aligned with the $y$ axis.

When the detonation tube contains a porous thrust surface, the detonation (initiated at or near the thrust surface) travels the length of the tube into the reactive mixture, followed by the Taylor wave. However, because of the flow through the thrust surface, some of the detonation products immediately begin to exhaust from the tube, resulting in a negative velocity $u_{3^{\prime}}$ (Fig. 7). To match this nonzero velocity, the Taylor wave must further expand the flow from $u_{2}$ to a speed $u_{3^{\prime}}$ in the direction opposite of the detonation wave propagation. This results in a corresponding plateau pressure $P_{3^{\prime}}$ at the porous thrust surface that is lower than in the case of a solid thrust surface (Fig. 4).

A reduction in the blocked area of the thrust surface results in an increase in the velocity of the flow that is exiting the tube in the direction opposite of the propagating detonation wave. As mentioned earlier, a corresponding decrease in the state $3^{\prime}$ pressure will occur and the impulse will decrease in accordance with Eq. (8). In the limit of a completely open thrust surface $(0 \% \mathrm{BR})$, the last characteristic of the Taylor wave is sonic at the tube exit, as illustrated in Fig. 8. No quasi-steady flow region is established behind the Taylor wave, and so the approximate impulse model of Eq. (4), which is 
used to derive Eq. (8), does not apply. However, regardless of the internal tube pressure for the case $(0 \% \mathrm{BR})$, the predicted impulse from Eq. (8) is zero because the thrust surface area is zero. We discuss this prediction of zero impulse in more detail while making comparisons to experimental data in a later section.

\section{Calculation of State $3^{\prime}$ Parameters}

To calculate state $3^{\prime}$, we assume that a quasi-steady flow with uniform parameters is established behind the Taylor wave. Mass must be conserved, so the condition that

$$
\rho u A(x)=\text { constant }
$$

must hold at all locations $x$ within the tube and through the porous thrust surface. The mass flux $\rho u$ is known to be maximized at the sonic condition. It follows from Eq. (9) that when the mass flux is a maximum, the area $A(x)$ is a minimum. This minimum area is called the choked area $A^{*}$ :

$$
\rho^{*} c^{*} A^{*}=\rho_{3^{\prime}} u_{3^{\prime}} A
$$

The terms with asterisks refer to sonic conditions. By substitution of the isentropic relations into Eq. (10), a relation between the choked area and Mach number $M_{3^{\prime}}$ arises:

$$
\frac{A}{A^{*}}=\frac{1}{M_{3^{\prime}}}\left[\frac{2}{\gamma+1}+\frac{\gamma-1}{\gamma+1}\left(M_{3^{\prime}}\right)^{2}\right]^{[(\gamma+1) / 2(\gamma-1)]}
$$

Our detonation tube has a constant cross-sectional area, so that the only flow restriction, or minimum $A(x)$, must occur at the thrust surface. Thus, the choked area $A^{*}$ is at $x=0$ along the tube (Fig. 1) and is equal to the product of a discharge coefficient and the physical dimensions of the experimental thrust surface. We assume an orifice discharge coefficient of one so that the choked area $A^{*}$ in Eq. (11) can be replaced by the physical dimensions of the free area of the thrust surface $A_{f}$ and used to calculate the Mach number $M_{3^{\prime}}$. The orifice discharge coefficient is known to depend on the Reynolds number for values less than approximately $5 \times 10^{3}$. For larger Reynolds numbers, the discharge coefficient has been measured to be only slightly less than unity. ${ }^{13,14}$ Although the cited data on discharge coefficients were generated by studies with a single orifice, the results may be extended to the case of a porous plate with regularly spaced holes. For this case, flow losses in perforated plates depend on the blockage ratio, plate thickness to hole diameter ratio, and Reynolds number. ${ }^{15}$ We estimate the Reynolds numbers upstream of the experimental thrust surfaces from the predicted state $3^{\prime}$ parameters. The viscosity was estimated for a mixture of water and carbon dioxide, corresponding to the complete combustion products of a stoichiometric mixture of ethylene and oxygen. For an initial pressure of $100 \mathrm{kPa}$, our Reynolds number estimate varied from $1.8 \times 10^{5}$ to $10^{6}$ for blockage ratios of 89 and $0 \%$, respectively. For an initial pressure of $40 \mathrm{kPa}$, our Reynolds number estimate varied from $4.2 \times 10^{4}$ to $3.9 \times 10^{5}$ for blockage ratios of 89 and $0 \%$, respectively. These values are significantly higher than $5 \times 10^{3}$, and so a discharge coefficient of one is a reasonable assumption.

The remaining flow parameters at state $3^{\prime}$ are calculated by consideration of a $C^{-}$characteristic through the Taylor wave from the Chapman-Jouguet state. The value of $\gamma$ used in these calculations reflects equilibrium conditions through the Taylor wave:

$$
u_{2}-\left[2 c_{2} /(\gamma-1)\right]=u_{3^{\prime}}-\left[2 c_{3^{\prime}} /(\gamma-1)\right]
$$

The flow velocity at state 2 can be related to the Chapman-Jouguet detonation velocity by the slope of the wave in Fig. 7:

$$
\begin{gathered}
x / t=u+c \\
x / c_{2} t=\left(u_{2}+c_{2}\right) / c_{2}=U_{\mathrm{CJ}} / c_{2}=M_{2}
\end{gathered}
$$

Substitution into Eq. (12) yields,

$$
U_{\mathrm{CJ}}-c_{2}-\left[2 c_{2} /(\gamma-1)\right]=u_{3^{\prime}}-\left[2 c_{3^{\prime}} /(\gamma-1)\right]
$$

The ratio of sound speeds across the Taylor wave are determined by manipulation of Eq. (15):

$$
\frac{c_{3^{\prime}}}{c_{2}}=\frac{M_{2}-[(\gamma+1) /(\gamma-1)]}{M_{3^{\prime}}-[2 /(\gamma-1)]}
$$

The isentropic relations are used to determine the corresponding pressure $P_{3^{\prime}}$ from the sound speed ratio

$$
P_{3^{\prime}}=P_{2}\left(c_{3^{\prime}} / c_{2}\right)^{2 \gamma /(\gamma-1)}
$$

\section{Results}

\section{Pressure and Ionization Data}

The pressure and ionization data are presented in this section to illustrate the tube's internal flowfield. Each of Figs. 9-16 represents a single experiment with a specified initial pressure and thrust surface blockage ratio. Increasing time is plotted on the $x$ axis, where zero corresponds to the time of spark ignition. The $y$ axis corresponds to pressure in units of megapascals and to axial distance along the detonation tube in units of decimeters. Thus, the internal edge of the thrust surface is located at a distance of zero (also denoted on Fig. 1) and the tube exit is located at a distance of $10.57 \mathrm{dm}$ (corresponding to a total tube length of $1.057 \mathrm{~m}$ ). The ionization data are plotted on the Figs. 9-16 by the dashed line containing the open square data points. When the detonation wave was observed to arrive at the

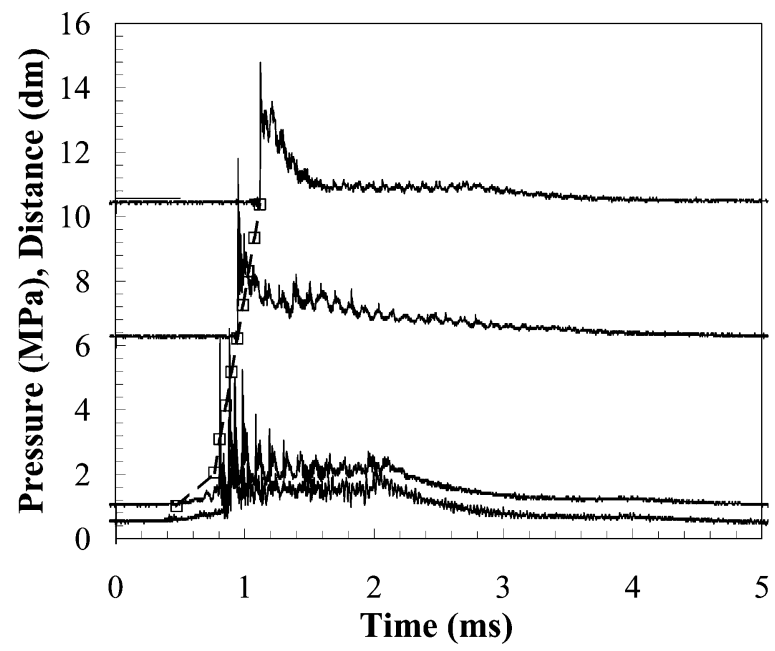

Fig. 9 Shot 209 with a thrust surface blockage ratio of $100 \%$ and initial pressure of $100 \mathrm{kPa}$.

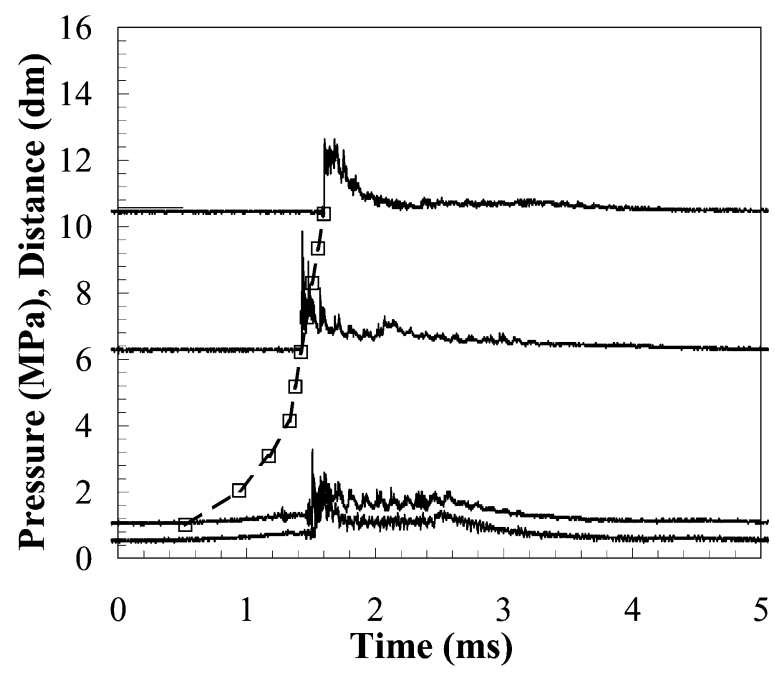

Fig. 10 Shot 207 with a thrust surface blockage ratio of $100 \%$ and initial pressure of $59.6 \mathrm{kPa}$. 


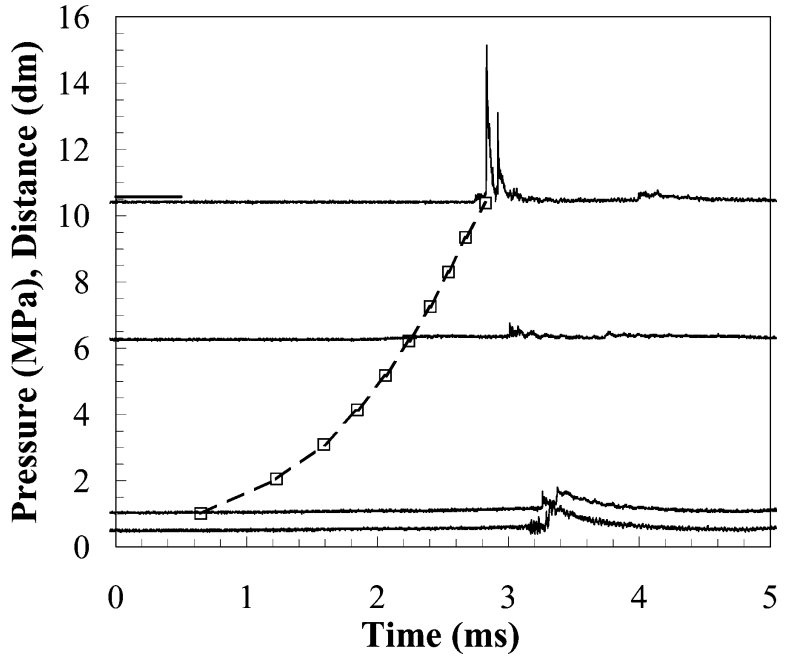

Fig. 11 Shot 206 with a thrust surface blockage ratio of $100 \%$ and initial pressure of $20.6 \mathrm{kPa}$.

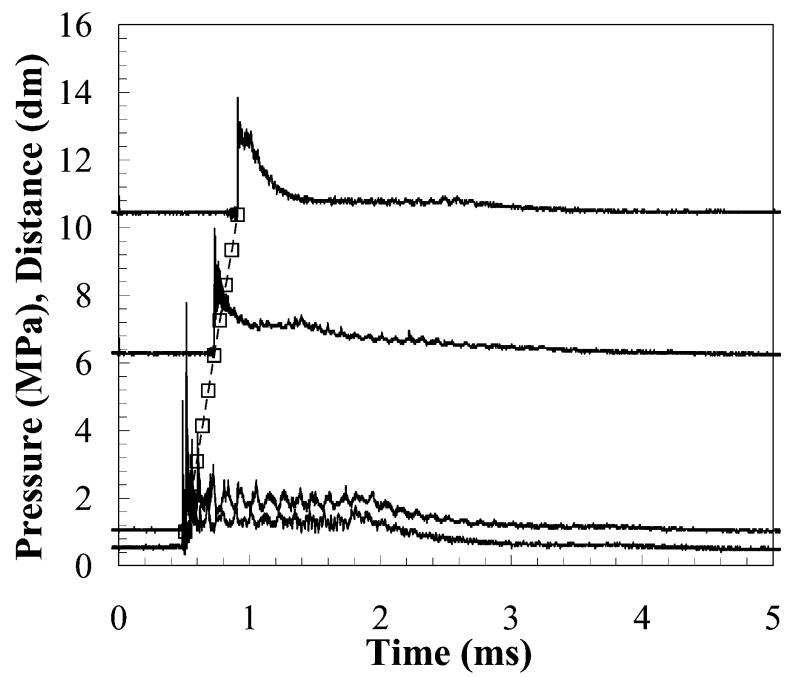

Fig. 12 Shot 203 with a thrust surface blockage ratio of $89.1 \%$ and initial pressure of $80.9 \mathrm{kPa}$.

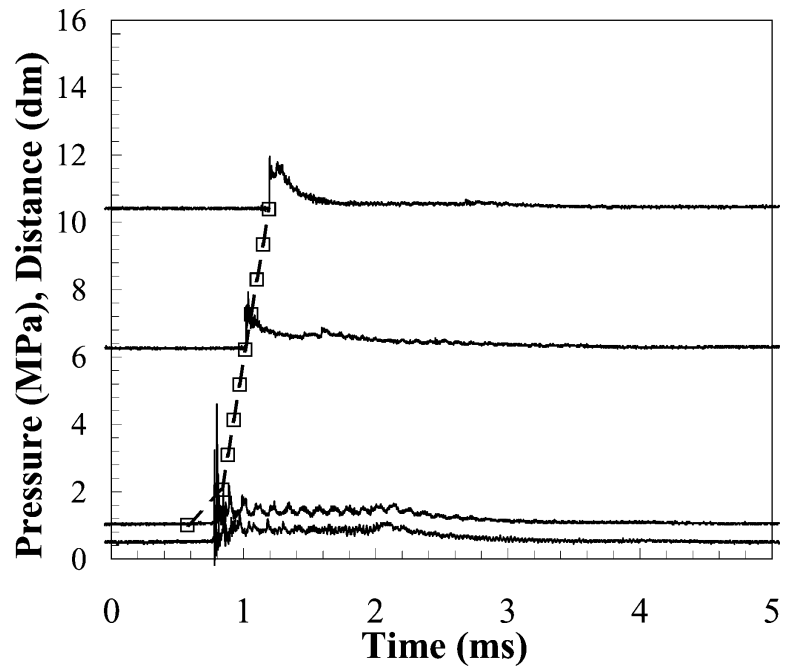

Fig. 13 Shot 202 with a thrust surface blockage ratio of $89.1 \%$ and initial pressure of $40.1 \mathrm{kPa}$.

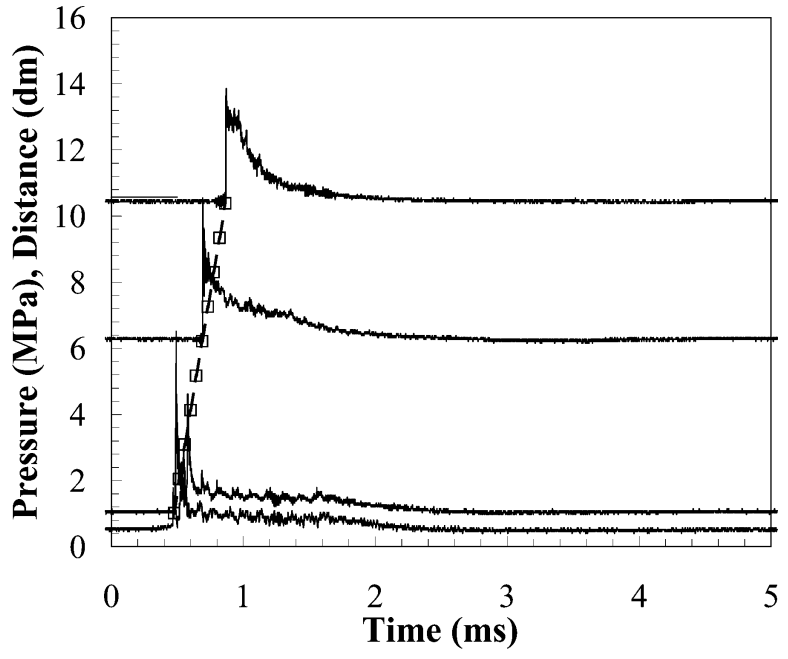

Fig. 14 Shot 237 with a thrust surface blockage ratio of $0 \%$ and initial pressure of $100 \mathrm{kPa}$.

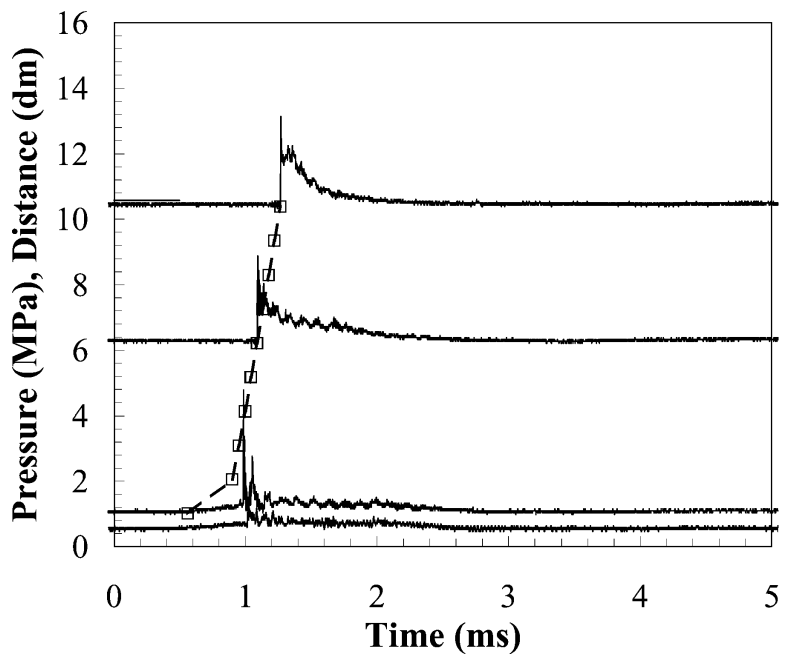

Fig. 15 Shot 235 with a thrust surface blockage ratio of $0 \%$ and initial pressure of $58.9 \mathrm{kPa}$.

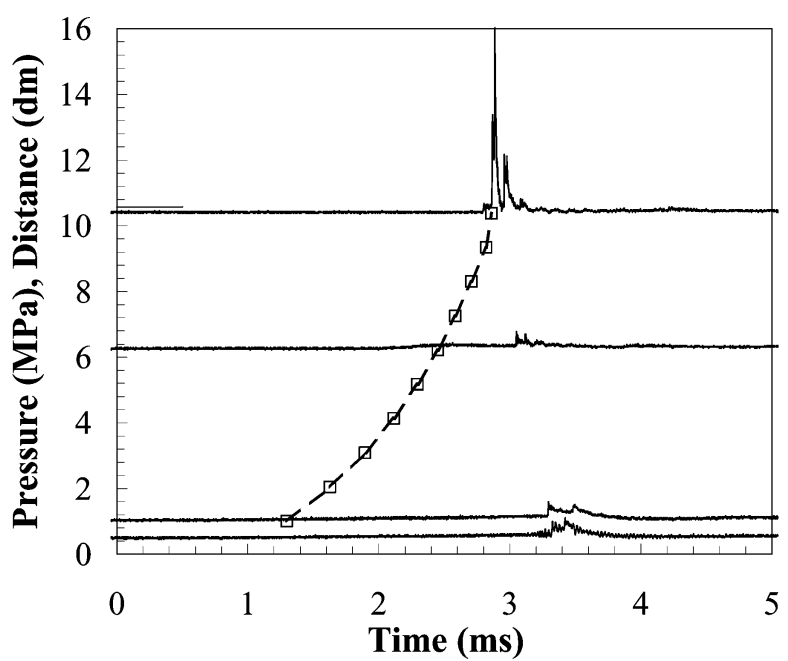

Fig. 16 Shot 236 with a thrust surface blockage ratio of $0 \%$ and initial pressure of $20.5 \mathrm{kPa}$. 
location of a specific ionization gauge, the time of arrival and location of that ionization gauge were recorded and plotted by a square data point. The curve connecting the data points illustrates the wave trajectory down the tube. Transition from an initial deflagration to a detonation is said to occur when the slope of this wave trajectory was equal to or greater than the Chapman-Jouguet detonation velocity. The maximum experimental uncertainty of this transition time is estimated to be $\pm 43 \mu$ s (Ref. 1).

The pressure histories measured from the four installed pressure transducers are also plotted. They have been offset along the $y$ axis a distance equal to their location from the internal edge of the thrust surface, as referenced in Fig. 1. For example, the first pressure transducer is located $43.4 \mathrm{~mm}$ (or $0.434 \mathrm{dm}$ ) from the internal edge of the thrust surface. Similarily, the second, third, and fourth transducers are located at distances of $100.8,621.5$, and $1038.0 \mathrm{~mm}$ from the thrust surface, respectively. Along an individual pressure trace, the absolute value of the pressure is determined relative to its $y$ axis offset. Thus, the absolute magnitude of the pressure at a given time is determined by subtraction of the pressure of the same trace at a time of zero.

High-frequency oscillations are observed in the pressure histories. They are most apparent in the tests with higher initial pressures, that is, 100,80 , and $60 \mathrm{kPa}$. The frequency of these oscillations can be explained by radial pressure oscillations with a period approximately equal to the ratio of the tube diameter to the product sound speed.

The experimental data with a solid thrust surface at different initial pressures appears in Figs. 9, 10, and 11. A period of flame acceleration after spark ignition is observed by an increasing slope of the wave trajectory as measured with the ionization gauges. At $100-\mathrm{kPa}$ initial pressure (Fig. 9), this time period of flame acceleration is the shortest, and transition to a detonation occurs by the second ionization gauge, approximately $0.803 \mathrm{~ms}$ after ignition. The second, third, and fourth pressure gauges show an abrupt overpressure of approximately $4 \mathrm{MPa}$, which is greater than the Chapman-Jouguet pressure of 3.4 MPa, indicating the presence of a detonation. When the initial pressure is reduced to $60 \mathrm{kPa}$ (Fig. 10), the DDT time increases to approximately $1.374 \mathrm{~ms}$ and transition occurs by the fourth ionization gauge. The overpressure spike, although not as large as in the data with $100-\mathrm{kPa}$ initial pressure, does exceed the expected Chapman-Jouguet pressure. As the initial pressure is further reduced to $20 \mathrm{kPa}$ (Fig. 11), the DDT event occurs at the end of the tube. Although the slope of the wave trajectory never exceeds the Chapman-Jouguet detonation speed, an abrupt pressure peak at the fourth pressure gauge is observed. The pressure peak is greater than the Chapman-Jouguet pressure, indicating that transition occurs in the distance between the last pressure gauge and the end of the tube.

Data for a thrust surface blockage ratio of $89.1 \%$ and initial pressures of approximately 80 and $40 \mathrm{kPa}$ appear in Figs. 12 and 13, respectively. In these cases, the DDT time increases to approximately $0.547 \mathrm{~ms}$ at $80 \mathrm{kPa}$ initial pressure and $0.878 \mathrm{~ms}$ at $40 \mathrm{kPa}$ initial pressure. Again, DDT time increases as the initial pressure decreases. Because of the thrust surface porosity, the arrival of the reflected expansion wave at approximately $5 \mathrm{~ms}$ is not as pronounced in the pressure histories as in the case of a solid thrust surface.

Data for an open thrust surface (0\% BR) with initial pressures of approximately 100, 60, and $20 \mathrm{kPa}$ appear in Figs. 14, 15, and 16, respectively. DDT time increases with a decrease in pressure. The transition event occurs by the first gauge at $100-\mathrm{kPa}$ initial pressure, the second gauge at $60-\mathrm{kPa}$ initial pressure, and the ninth ionization gauge at $20-\mathrm{kPa}$ initial pressure.

Figure 17 further illustrates the effect of decreasing pressure on DDT time. All data points at the different experimental blockage ratios are plotted. The variation in DDT time is at least $1000 \mu \mathrm{s}$ over the range of initial pressures tested, regardless of blockage ratio. This variation is greater than $100 \%$ of the average DDT time at a given blockage ratio. Figure 18 plots the same data as a function of blockage ratio. At a given initial pressure, the variation in DDT time is no larger than $76 \%$ of the average DDT time at a given initial pressure (Table 2). From Figs. 17 and 18, the DDT time is
Table 2 Variation and average DDT time over range of tested blockage ratios at each initial pressure

\begin{tabular}{lccc}
\hline \hline $\begin{array}{c}P_{1}, \\
\mathrm{kPa}\end{array}$ & $\begin{array}{c}\text { Variation in } \\
\text { DDT time, } \mu \mathrm{s}\end{array}$ & $\begin{array}{c}\text { Average DDT } \\
\text { time, } \mu \mathrm{s}\end{array}$ & Percent \\
\hline 100 & 293 & 650 & 45 \\
80 & 358 & 709 & 50 \\
60 & 663 & 873 & 76 \\
40 & $83^{\mathrm{a}}$ & 883 & 9 \\
20 & 786 & 2467 & 32 \\
\hline \hline
\end{tabular}

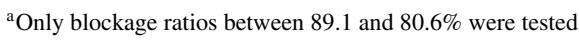

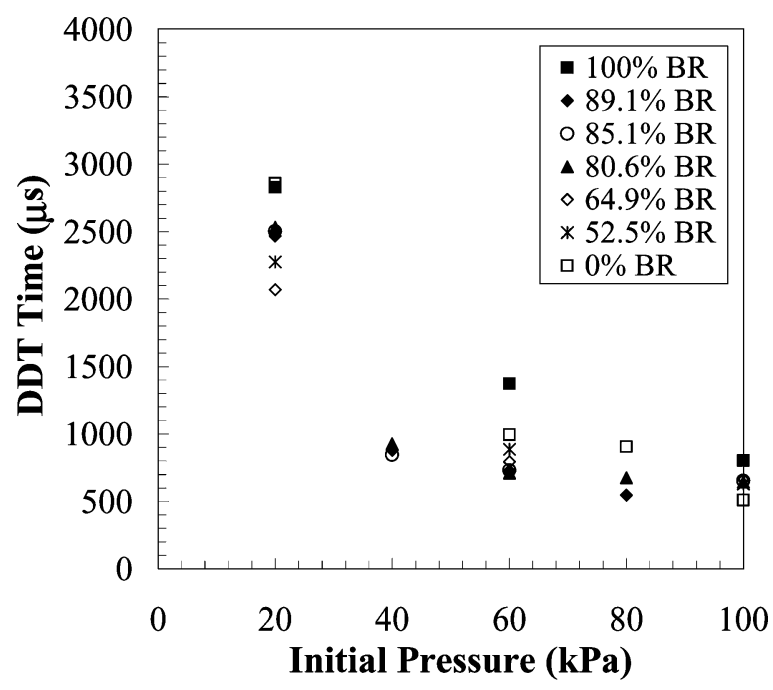

Fig. 17 DDT time as a function of initial pressure.

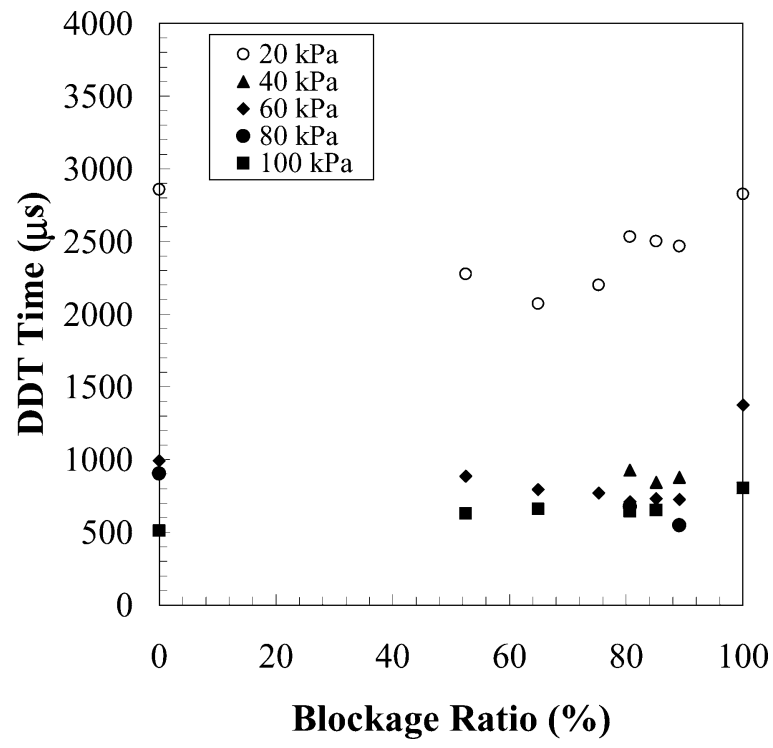

Fig. 18 DDT time as a function of blockage ratio.

more dependent on the mixture's initial pressure than on the thrust surface blockage ratio.

\section{Plateau Pressure Measurements}

The calculated values of the thrust surface pressure $P_{3^{\prime}}$ are compared to the measured values obtained by time averaging the thrust surface pressure history. A subregion of the experimentally measured plateau region not affected by pressure oscillations from the passage of the detonation wave or the arrival of the reflected expansion was averaged to obtain a better estimate of the $P_{3^{\prime}}$ value. Results are plotted in Fig. 19 as a function of blockage ratio and the predicted values are within $\pm 15 \%$ of the experimental values for 


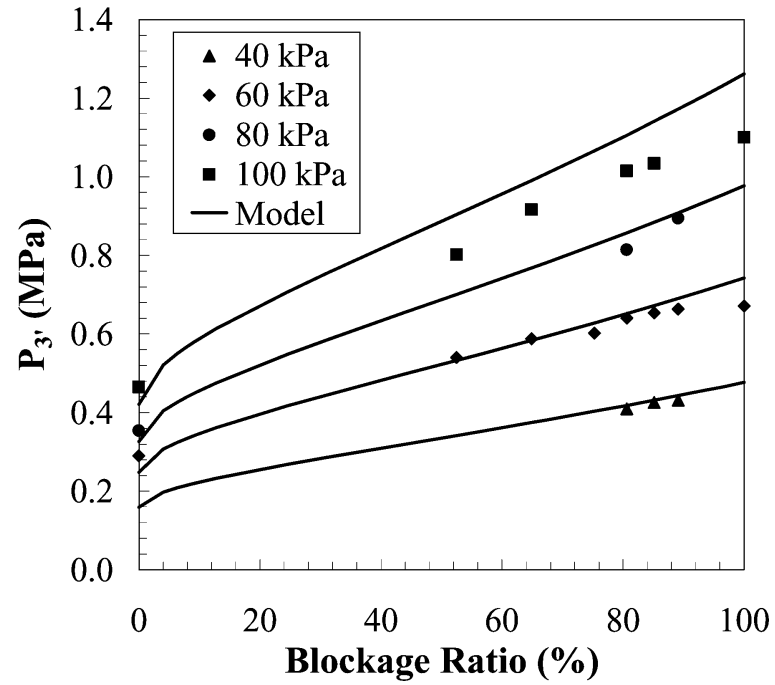

Fig. 19 Plateau pressure $P_{3^{\prime}}$ vs blockage ratio, the lines correspond to the model predictions of $P_{3^{\prime}}$ as described by Eqs. (11-17).

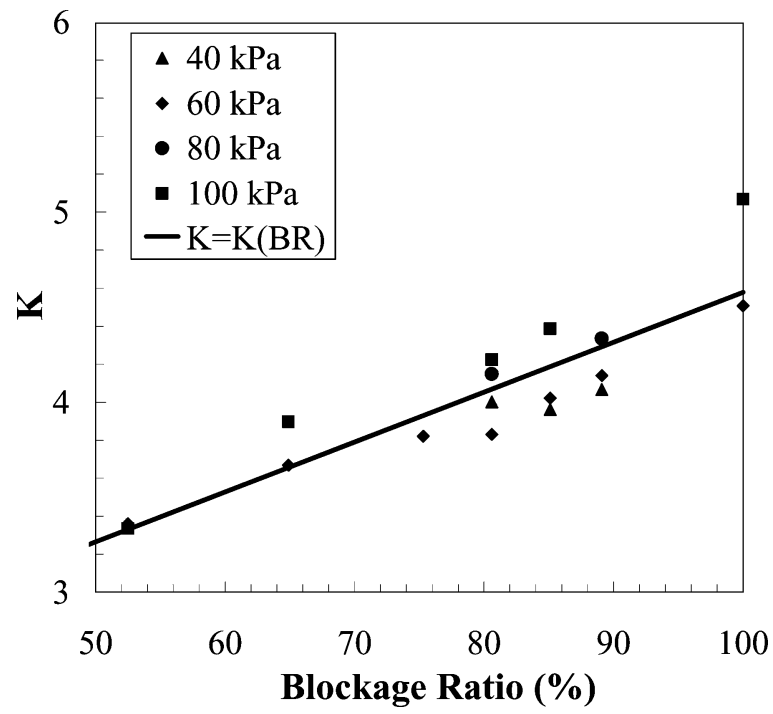

Fig. 20 Model constant $K$ vs blockage ratio, the line corresponds to the linear relationship, $K=2.63 \times \mathrm{BR}+1.95$.

all blockage ratios. The difference between the experimental and predicted values at a blockage ratio of $0 \%$ is expected because of the lack of a quasi-steady flow region. This is observed in the experimental pressure traces (Figs. 14-16) and made an estimate of the plateau pressure difficult. The experimental $P_{3^{\prime}}$ data decreased $27 \%$ at an initial pressure of $100 \mathrm{kPa}$ and $19 \%$ at an initial pressure of $60 \mathrm{kPa}$ as the blockage ratio decreased to $52.5 \%$.

\section{Evaluation of Constant $K$}

The blowdown time for a detonation tube with a porous thrust surface is expected to be shorter than the blowdown time in a tube with a solid thrust surface. This is due to the additional mass flow out of the tube through the thrust surface holes. As a result, the model constant $K$ of Eq. (8) does not equal a constant value of 4.3 as was previously ${ }^{12}$ determined, but should decrease as the thrust surface blockage ratio decreases. Figure 20 shows the variation of $K$ as a function of the blockage ratio. The experimental measurements of the impulse and plateau pressure are used to calculate $K$,

$$
K=\frac{I_{V} U_{\mathrm{CJ}}}{\left(P_{3^{\prime}}-P_{0}\right)\left(1-A_{f} / A\right)}
$$

From Fig. 20, the variation of $K$ can be written as a linear function of the blockage ratio.

$$
K=2.63 \times \mathrm{BR}+1.95
$$

This relationship is used with Eq. (8) in the following impulse predictions.

\section{Impulse Measurements}

The experimental data are compared with the model predictions of Eqs. (8) and (19) as a function of blockage ratio in terms of the impulse per unit volume (Fig. 21) and mixture-based specific impulse (Fig. 22). The impulse per unit volume and specific impulse are related by

$$
I_{\mathrm{SP}}=I / V g \rho_{1}=I_{V} / g \rho_{1}
$$

Decreasing the blockage ratio to $52.5 \%$ results in a $76 \%$ decrease in the normalized impulse at an initial pressure of $100 \mathrm{kPa}$ and a $68 \%$ decrease in the normalized impulse at an initial pressure of $60 \mathrm{kPa}$. The model predictions of normalized impulse are within $\pm 15 \%$ of the experimental data for blockage ratios greater than $0 \%$.

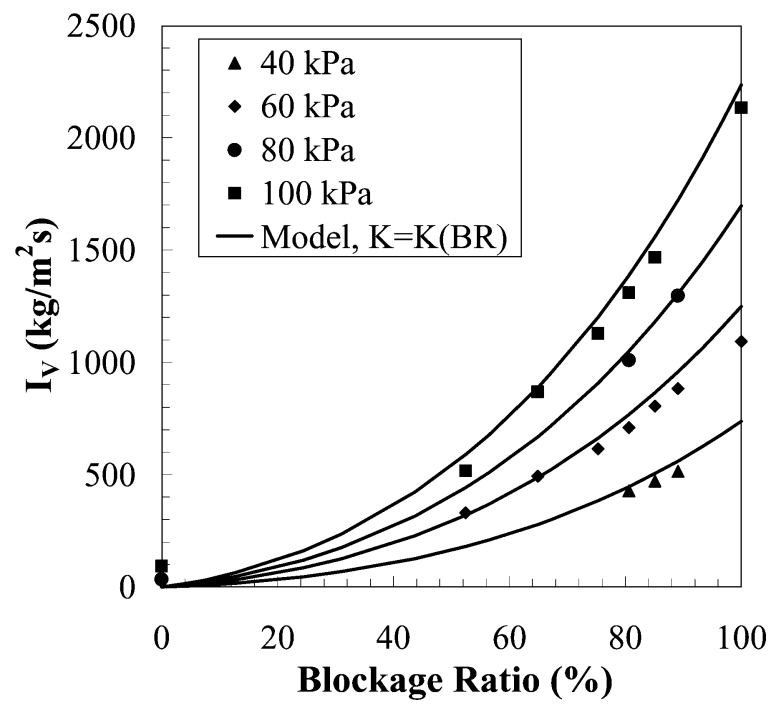

Fig. 21 Impulse measurements as a function of blockage ratio at varying initial pressures, lines correspond to the model predictions of $I_{V}$ as described by Eqs. (8) and (19).

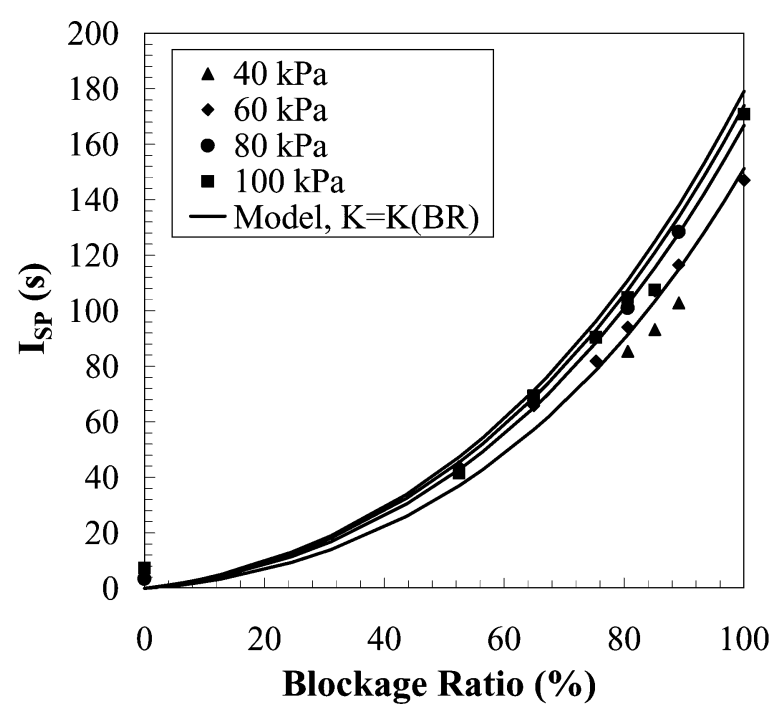

Fig. 22 Specific impulse measurements as a function of blockage ratio for thrust surfaces at varying initial pressures, lines correspond to the model predictions of $I_{\mathrm{SP}}$ as described by Eqs. (8), (19), and (20). 
Table 3 Estimated and measured normalized impulse for a completely open thrust surface (0\% BR)

\begin{tabular}{lc}
\hline \hline$P_{1}, \mathrm{kPa}$ & $I_{V}, \mathrm{~kg} / \mathrm{m}^{2} \mathrm{~s}$ \\
\hline 100 & 91.6 \\
80 & 33.0 \\
60 & 25.0 \\
\hline \hline
\end{tabular}

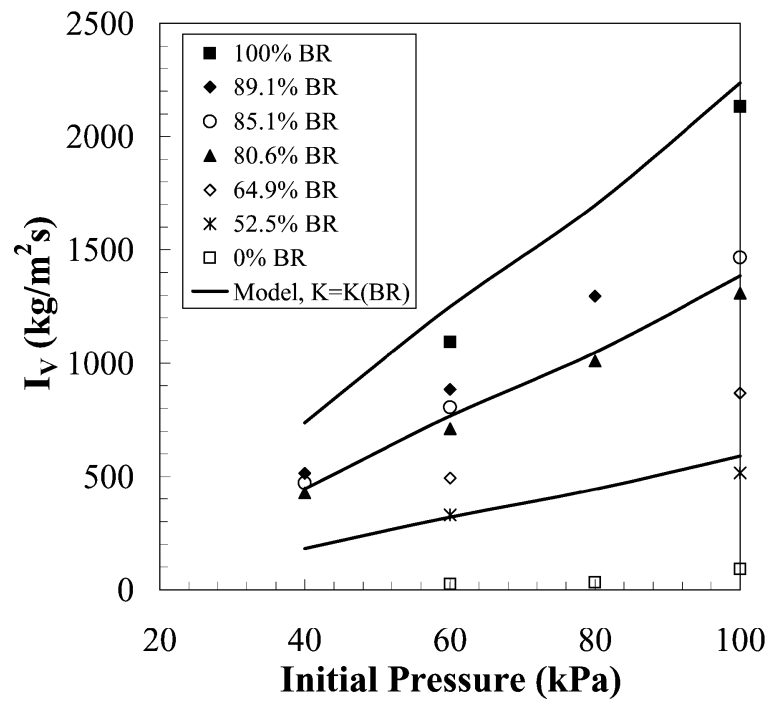

Fig. 23 Impulse measurements as a function of initial pressure for thrust surfaces of varying blockage ratios, model predictions are plotted as lines for blockage ratios of $\mathbf{1 0 0 , 8 0 . 6}$, and $\mathbf{5 2 . 5 \%}$.

Figure 23 shows the experimental impulse values as a function of initial pressure for the different experimental blockage ratios, illustrating the increase in impulse with initial pressure. The model predictions of Eqs. (8) and (19) are shown for BR of 100, 80.6, and $52.5 \%$ for comparison with the experimental data.

Experimental impulse data were obtained for a completely open thrust surface (Table 3). At a $0 \% \mathrm{BR}$, the model predicts zero impulse because there is no thrust surface for a pressure differential to act on. However, additional $x$-direction forces such as wall shear stresses and forces on the wall thickness due to shock diffraction outside the tube may act on the control volume and should be included in the analysis of Eq. (5). We conducted estimates of these additional forces and found that they are likely the cause of the nonzero impulse measured in a completely open tube (Table 3 ). However, the results were largely inconclusive due to the complexity of the internal flow.

The measured impulse data for a $100 \%$ BR thrust surface were compared to previous experimental data ${ }^{1}$ at the same initial conditions. Over the range of initial pressures tested, the results of this study were within $3 \%$ of the previously measured values. The tubemounted fixure in which the different thrust surfaces were installed is most likely the cause of this discrepancy. Care was taken during the machining of the thrust surfaces to ensure a very close fit between the outer circumference of the thrust surface and the mating surface of the fixture, however, this seal was not perfect, as observed by the state of the upstream diaphragm after tests with the $100 \%$ BR thrust surface. In fact, the upstream diaphragm was observed to burst entirely during tests at $100 \mathrm{kPa}$ initial pressure, a small hole was observed in the tests at $60 \mathrm{kPa}$ initial pressure, and no disturbance of the diaphragm was observed for the tests at $20 \mathrm{kPa}$ initial pressure. It is expected that the boundary condition of zero velocity at the thrust surface was not strictly met for the tests with higher initial pressure, but this velocity was reasonably small as demonstrated by the agreement with the previous impulse data. ${ }^{1}$

As mentioned in the discussion of the tested thrust surfaces, an additional thrust surface with a 4-hole arrangement was also tested (Fig. 2). This thrust surface had a blockage ratio of $88.9 \%$ and was tested at varying initial pressures. A comparison of the impulse

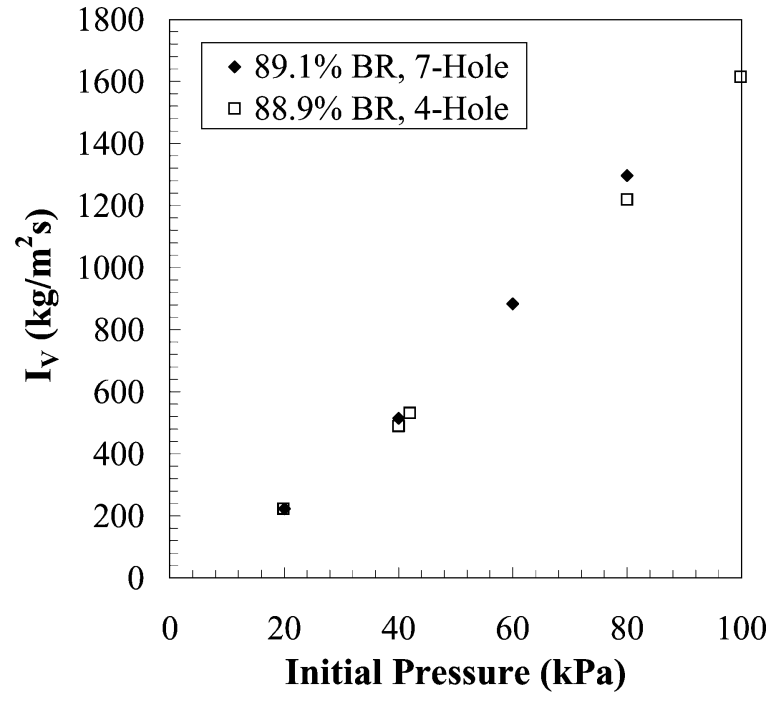

Fig. 24 Impulse measurements as a function of initial pressure for thrust surfaces with similar blockage ratios and different hole configurations.

between the two thrust surfaces with different hole arrangements and similar blockage ratios illustrates that hole orientation has little effect on the measured impulse (Fig. 24). Instead, the important factor is the area ratio $A_{f} / A$. Although only one blockage ratio was tested, this seems to support the work of Kolodzie and Van Winkle who also tested many different hole orientations in their perforated plates. They observed no dependence on hole orientation. ${ }^{16}$

\section{Conclusions}

Single-cycle impulse measurements were obtained with a detonation tube containing a porous thrust surface hung in a ballistic pendulum arrangement. Experiments were completed with blockage ratios between 0 and $100 \%$ and initial pressures between 20 and $100 \mathrm{kPa}$ with stoichiometric ethylene-oxygen mixtures. The time required for the initial deflagration to transition to a detonation was found to be more dependent on the initial pressure than on the blockage ratio. The measured impulse was found to decrease as the thrust surface blockage ratio decreased and as the initial pressure decreased. A theoretical model was developed to predict the impulse from a detonation tube with a porous thrust surface and compared to the experimental data. The model assumed the flow exiting the tube through the porous thrust surface was choked and supplied by a region of quasi-steady flow behind the Taylor wave. A method for predicting the thrust surface plateau pressure was discussed. The model is within $\pm 15 \%$ of the experimental data for blockage ratios greater than $0 \%$.

This research provides information for PDE inlet designers to help predict the maximum losses in impulse that may occur. Although specific losses must be evaluated on an individual basis, this research highlights the importance of inlet design. Thus, PDE performance not only depends on the impulse obtained from detonating a specific mixture, but also designing the supporting engine components to transfer this chemical energy into thrust effectively.

\section{Acknowledgment}

This work was supported by the U.S. Office of Naval Research Multidisciplinary University Research Initiative Multidisciplinary Study of Pulse Detonation Engine (N00014-02-1-0589), and General Electric Contract GE-PO A02 81655 under DABT-63-0-0001.

\section{References}

${ }^{1}$ Cooper, M., Jackson, S., Austin, J., Wintenberger, E., and Shepherd, J. E., "Direct Experimental Impulse Measurements for Detonations and Deflagrations," Journal of Propulsion and Power, Vol. 18, No. 5, 2002, pp. 1033-1041. 
${ }^{2}$ Lindstedt, R. P., and Michels, H. J., "Deflagration to Detonation Transitions and Strong Deflagrations in Alkane and Alkene Air Mixtures," Combustion and Flame, Vol. 76, May 1989, pp. 169-181.

${ }^{3}$ Harris, P. G., Farinaccio, R., Stowe, R. A., Higgins, A. J., Thibault, P. A., and Laviolette, J. P., "The Effect of DDT Distance on Impulse in a Detonation Tube," AIAA Paper 2001-3467, July 2001.

${ }^{4}$ Zitoun, R., and Desbordes, D., "Propulsive Performances of Pulsed Detonations," Combustion Science and Technology, Vol. 144, No. 1, 1999, pp. 93-114.

${ }^{5}$ Zhdan, S. A., Mitrofanov, V. V., and Sychev, A. I., "Reactive Impulse from the Explosion of a Gas Mixture in a Semi-Infinite Space," Combustion, Explosion, and Shock Waves, Vol. 30, No. 5, 1994, pp. 657-663.

${ }^{6}$ Falempin, F., Bouchaud, D., Forrat, B., Desbordes, D., and Daniau, E., "Pulsed Detonation Engine Possible Application to Low Cost Tactical Missile and to Space Launcher," AIAA Paper 2001-3815, July 2001.

${ }^{7}$ Cooper, M., and Shepherd, J. E., "The Effect of Nozzles and Extensions on Detonation Tube Performance," AIAA Paper 02-3628, July 2002.

${ }^{8}$ Bussing, T., "A Rotary Valve Multiple Pulse Detonation Engine (RVMPDE),” AIAA Paper 95-2577, July 1995.

${ }^{9}$ Aarnio, M. J., Hinkey, J. B., and Bussing, T. R. A., "Multiple Cycle Detonation Experiments During the Development of a Pulse Detonation Engine," AIAA Paper 96-3263, July 1996.
${ }^{10}$ McManus, K., Furlong, E., Leyva, I., and Sanderson, S., "MEMS Based Pulse Detonation Engine for Small Scale Propulsion Applications," AIAA Paper 2001-3469, July 2001.

${ }^{11}$ Schauer, F., Stutrud, J., and Bradley, R., "Detonation Initiation Studies and Performance Results for Pulsed Detonation Engines," AIAA Paper 20011129, Jan. 2001.

${ }^{12}$ Wintenberger, E., Austin, J., Cooper, M., Jackson, S., and Shepherd, J. E., "An Analytical Model for the Impulse of a Single-Cycle Pulse Detonation Engine," Journal of Propulsion and Power, Vol. 19, No. 1, 2003, pp. $22-38$

${ }^{13}$ Kuluva, N. M., and Hosack, G. A., "Supersonic Nozzle Discharge Coefficients at Low Reynolds Numbers," AIAA Journal, Vol. 9, No. 9, 1971, pp. 1876-1879.

${ }^{14}$ Kayser, J. C., and Shambaugh, R. L., "Discharge Coefficients for Compressible Flow Through Small-Diameter Orifices and Convergent Nozzles," Chemical Engineering Science, Vol. 46, No. 7, 1991, pp. 1697-1711.

${ }^{15}$ Gan, G., and Riffat, S. B., "Pressure Loss Characteristics of Orifice and Perforated Plates," Experimental Thermal and Fluid Science, Vol. 14, No. 2, 1997, pp. 160-165.

${ }^{16}$ Kolodzie, P. A. Jr., and Van Winkle, M., "Discharge Coefficients Through Perforated Plates," AICE Journal, Vol. 3, No. 3, 1957, pp. 305-312.

\section{0-YEAR MEETNG PAPEB ABCHIISS ONLNE}

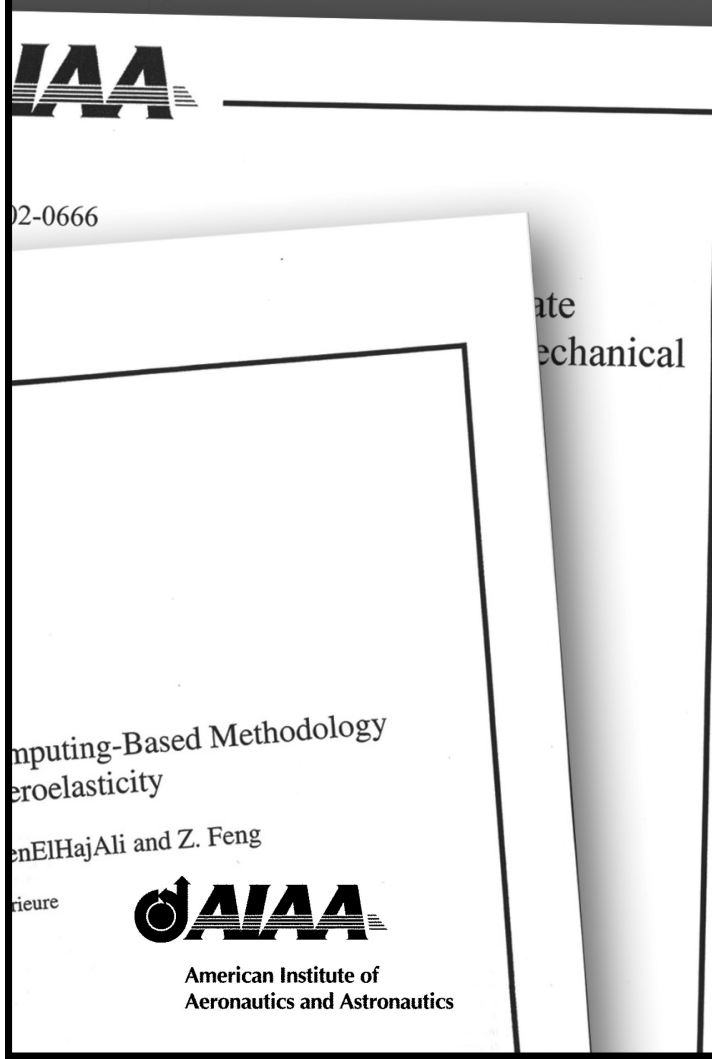

Each year, AIAA publishes more than 4000 technical papers presented at AIAA conferences. These papers contain the most recent discoveries in aerospace and related fields. No other organization offers this depth and breadth in the aerospace field.

\section{You now have immediate access to more} than 100,000 technical papers online

Beginning with 1963 and adding about 4,000 papers every year, AIAA's online archive allows you to search for the latest developments in:

Astrodynamics • Aerodynamics • Guidance • Structures • Fluids • Propulsion • Controls • Modeling and Simulation $\cdot$ Flight Mechanics • and more..

Search and purchase only those papers that fit your needs. Papers are delivered in pdf format. Search by:

Title - Keyword - Author A AIAA Paper Number - Conference Title $\cdot$ Publication Year 